\title{
Posição encyclopedica do direito internacional publico
}

\author{
SUMMARIO \\ $\$ 1.0$ Posição encyclopedica do direito internacional \\ publico na classificação das sciencias de Au- \\ gusto Comte. \\ $\S 20$ Posição encyclopedica do direito internacio- \\ nal publico na classificação das sciencias de \\ Herbert Spencer. \\ § $3 .^{\circ}$ Posição encyclopedica do direito internacio- \\ nal publico no quadro das sciencias juridicas.
}

$\$ 1 .^{\circ}$

\section{Posição encyclopedica do direito intertracional publico na classificação das sciencias de stugusio Comte}

Dividirei a exposição da these em tres partes:

a) posição encyclopedica do direito internacional publico na classificação das sciencias de Augusto Comte ;

b) posição encyclopedica do direito internacional publico na classificação das sciencias de Herbert Spencer, e

c) posição encyclopedica do direito internacional publico no quadro das sciencias juridicas.

As duas primeiras secções vêm expostas nos meus Ensaios de philosophia do direito, \$\$117 e 119. O 
criterio da classificação das sciencias de Comte é a generalidade decrescente e a complexidade crescente dos phenomenos por ellas estudados. De accôrdo com esse criterio, apresenta o grande philosopho esta classificação, a partir da sciencia mais simples para a mais complexa:
a) Mathematica,
b) Astronomia,
c) Physica,
d) Chimica,
e) Biologia e
f) Sociologia.

Nesta classificação, que abalou o mundo scientifico, o direito internacional publico fica incluido na sociologia, porquanto, Comte concebeu esta sciencia como a unica sciencia social, considerando as differentes sciencias sociaes particulares como capitulos della.

\section{$\S 2 .^{\circ}$}

\section{Posição encyclopedica do direito internacional publico na classiticação das sciencias de Herbert Spencer}

Spencer rejeita a classificação das sciencias de Comte, e apresenta uma outra.

Em primeiro logar, divide elle as sciencias em duas grandes classes:

a) sciencias que têm por objecto as relações abstractas sob as quaes os phenomenos se nos apresentam, e nomenos.

b) sciencias que têm por objecto os proprios phe-

Essas relações abstractas são as de espaço e de tempo, isto é, são as relações de coexistencia e de successão. O espaço é a ideia abstracta que abrange todas as relações de coexistencia. E o tempo a ideia abstracta que abrange todas as relações de successão. 
As sciencias que se occupam só do espaço e do tempo divergem muito das sciencias que se occupam das coisas comprehendidas no espaço e no tempo.

Aquellas são a logica e a mathematica.

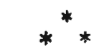

As da segunda classe, que têm por objecto os proprios phenomenos, as proprias coisas contidas no espaço e no tempo, subdividem-se em:

a) sciencias que estudam isoladamente um ou outro dos elementos dos phenomenos, e

b) sciencias que estudam englobadamente o conjuncto dos elementos dos mesmos phenomenos.

Ou por outras palavras :

as sciencias do primeiro grupo desta subdivisão estudam destacadamente um dos varios modos de manifestação da força productora dos phenomenos.

As do segundo grupo estudam em seu conjuncto todos esses modos de manifestação da força.

No primeiro caso, buscam-se as leis de cada modo de força, agindo só, com abstracção dos outros modos.

No segundo, buscam-se todas as leis reguladoras dos phenomenos, que são explicados em todas as suas partes como resultantes do conjuncto de manifestações simultaneas da força.

As verdades no primeiro caso são concretas, porque versam sobre uma realidade objectiva, mas são tambem abstractas, porque concernem a modos de existencia considerados separadamente uns dos outros.

No segundo caso, ellas são propriamente verdades concretas, porque representam os factos. em seu estado de combinação, como existem realmente em a natureza. Aquellas são:

a) a mechanica,

b) a physica,

c) chimica, etc. 
Estas são:

a) a astronomia,

b) a geologia,

c) a biologia,

d) a psychologia,

e) a sociologia e

f) a moral.

Póde-se, pois, formar o seguinte quadro synoptico:

SCIENCIA $\begin{cases}\text { Abstracta } & \left\{\begin{array}{l}\text { Logica } \\ \text { e } \\ \text { Mathematica }\end{array}\right. \\ \text { Abstracto-concreta } & \left\{\begin{array}{l}\text { Mechanica, } \\ \text { Physica, } \\ \text { Chimica, etc. }\end{array}\right. \\ \text { Concreta. } & \left\{\begin{array}{l}\text { Astronomia, } \\ \text { Geologia, } \\ \text { Biologia, } \\ \text { Psychologia, } \\ \text { Sociologia e } \\ \text { Moral }\end{array}\right.\end{cases}$

Nesta classificação, o direito internacional publico fica incluido na moral, como parte desta, que é.

Já se não concebe a sociologia como a sciencia social unica. Hoje, sociologia é a sciencia fundamental, que estuda as leis geraes, basicas, reguladoras da origem, crescimento, estructura e actividade da sociedade.

Em face desta concepção, que é a verdadeira, as sciencias sociaes particulares ou especiaes, como o direito, a politica, a economia politica, etc., não são secções da sociologia, mas sciencias autonomas.

$$
\S 3 .^{\circ}
$$

\section{Posição encyclopedica do direito intermacional publico no quadro das sciencias juridicas}

Vejamos finalmente a posição encyclopedica do direito internacional publico no quadro das sciencias juridicas. 


\section{$-297-$}

\section{CRITERIO DAS DIVISÕES}

A logica nos ensina que as divisões e clissificações variam conforme o criterio escolhido por quem divide ou classifica, e que deste criterio depende a maior ou menor importancia e utilidade da divisão ou da classificação. Tal seja o criterio escolhido para base da divisão ou da classificação, que esta carecerá, por completo, de importancia e utilidade, podendo mesmo chegar a ser pueril. Acompanhando-se a marcha das differentes correntes do pensamento, verificase que as divisões e classificações reflectem o cunho das tendencias mentaes de cada época, a feição de cada escola philosophica, bem como as verdades e os erros em cada uma dominantes.

\section{DIVISÕES DO DIREITO}

Sob o ponto de vista da natureza das relações que regula, divide-se o direito em:

a) publico e

b) privado,

segundo ditas relações exprimem condições de vida e desenvolvimento da sociedade, ou do individuo (Meus Ensaios citados, $\S 121$, pags 752-3).

Sob o ponto de vista da territorialidade ou do espaço em que se faz sentir a sua efficacia, divide-se em:

a) interno $\mathrm{e}$

b) externo ou:

a) nacional e

b) internacional (Meus Ensaios, loco citato).

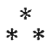

$\mathrm{O}$ direito internacional publico, regulador das relações que exprimem condições de vida e desenvolvimento do estado como unidade mundial, e da socieda- 
de dos estados, é, pois, um ramo do direito publico, aliás muito recente, e um ramo do direito externo. Crearam-no as exigencias progressivas da vida internacional moderna.

\section{FonTES}

A presente these vem exposta nos meus «Ensaios citados», $\S 117$, pags. $680-8 ; \S 119$, pags. $697-8$, e $\S 121$, pags. $752-3$. 